\title{
Effects of connective tissue growth factor on prostate cancer bone metastasis and osteoblast differentiation
}

\author{
SHUANGLI ZHANG ${ }^{1}$, BAOLIN LI $^{2}$, WEI TANG $^{3}$, LINYING NI $^{4}$, HUILI MA $^{5}$, MING LU $^{6}$ and QINGGANG MENG ${ }^{2}$ \\ ${ }^{1}$ Department of Orthopaedic Surgery, The Fourth Hospital of Harbin Medical University, Harbin, Heilongjiang 150086; \\ ${ }^{2}$ Department of Orthopaedic Surgery, Harbin The First Hospital, Harbin Medical University, Harbin, Heilongjiang 150010; \\ ${ }^{3}$ Department of Orthopaedic Surgery, The Second People's Hospital of Rizhao, Rizhao, Shandong 276807; \\ ${ }^{4}$ Department of Orthopaedic Surgery, Harbin Medical University Cancer Hospital, Harbin, Heilongjiang 150081; \\ ${ }^{5}$ Department of Orthopaedic Surgery, Binzhou Medical University Hospital, Binzhou, Shandong 256603; \\ ${ }^{6}$ Department of Oncological Surgery, The First Hospital of Qiqihaer City, Qiqihaer, Heilongjiang 161005, P.R. China
}

Received September 29, 2016; Accepted September 22, 2017

DOI: $10.3892 / \mathrm{ol} .2018 .8960$

\begin{abstract}
Previous studies have demonstrated that connective tissue growth factor (CTGF) is expressed at increased levels in prostate cancer bone metastasis mouse models and patients with prostate cancer which metastasizes to the bone; however, the underlying molecular mechanism(s) remain unknown. The present study investigated the function of CTGF in osteoblast differentiation and its effect on prostate cancer bone metastasis by analyzing $C T G F$ gene expression and transcription at different levels of invasion, metastasis of prostate cancer cells, and the influence of CTGF on proliferation and xenotransplantation. A mouse model demonstrating bone metastasis was used to investigate the function(s) of CTGF in bone metastasis and osteoblast differentiation. Results demonstrated that $C T G F$ expression was increased in association with high bone metastasis in prostate cancer cells, and its expression was significantly decreased in whole cell lysates. $C T G F$ expression in prostate cancer cells with high levels of bone metastasis was increased 1.9-fold compared with prostate cancer cells with low levels of bone metastasis. The expression of CTGF in mesenchymal cells was markedly
\end{abstract}

Correspondence to: Dr Qinggang Meng, Department of Orthopaedic Surgery, Harbin The First Hospital, Harbin Medical University, 157 Health Road, Harbin, Heilongjiang 150010, P.R. China

E-mail: shuanglizhang244@163.com

Professor Ming Lu, Department of Oncological Surgery, The First Hospital of Qiqihaer City, 30 Park Road, Jianhua, Qiqihaer, Heilongjiang 161005, P.R. China

E-mail: fengyl151129@126.com

Abbreviations: CTGF, connective tissue growth factor; ALP, alkaline phosphatase; AA, ascorbic acid

Key words: connective tissue growth factor, osteoblast differentiation, prostate cancer, bone metastasis, xenotransplantation increased compared with epithelial cells. Results indicated that the increased expression of CTGF does not affect the proliferation of tumor cells and possesses no influence on tumor volume. Control and CTGF plasmids were transfected into RM1 cells and led to 4 and $17 \%$ bone lesions, respectively. Increased expression of CTGF significantly enlarged the tumor area in the bone metastatic position compared with the control. Positive areas of alkaline phosphatase were significantly decreased as the concentration of CTGF increased. The results of the present study demonstrated that CTGF promotes prostate carcinoma to metastasize in the bone by dysregulating osteoblast differentiation.

\section{Introduction}

Prostate cancer is one of the most common cancers among men, which affects one in seven men in the US (1). Theoretically, prostate cancer cells may spread anywhere in the body. If prostate cancer spreads to other parts of the body, bone is the preferred location for prostate cancer to metastasize to, which results in complications including bone pain, pathological fractures, spinal compression and hypercalcemia (2). Osteogenesis serves an important function in osteolytic bone lesions.

Connective tissue growth factor (CTGF) is a matricellular protein that belongs to the extracellular matrix-associated heparin-binding protein family $(3,4)$, which has notable functions in numerous different biological processes, including cell migration and proliferation (5). Previous experimental studies demonstrate that CTGF expression levels are high in mouse models and patients with primary prostate cancer that have metastasized to the bone (6). CTGF possesses multiple functions in different types of cancer cell (7).

Previous studies have demonstrated that CTGF possesses an inhibitory function in the development of brain glioma, melanoma and prostate cancer cells (8). However, in contrast, a previous study has identified that CTGF has a facilitating effect on the metastasis of melanoma in addition to being able to promote the proliferation, migration and metastasis of Ewing sarcoma cells, and increasing expression levels result in an undesirable prognosis (9). To the best of our knowledge, the 
functional mechanisms of CTGF in association with prostate cancer metastasizing within the bone remain unclear.

The present study investigated the effect of CTGF on prostate cancer bone metastasis using RM1 murine prostate cancer cell line and analyzed the underlying molecular mechanisms regarding to mouse osteoblast differentiation dysregulation.

\section{Materials and methods}

Cell culture. All experiments of the present study were approved by the ethics committee of The First Hospital of Qiqihar (Heilongjiang, China; no. 2015017). Mouse prostate cancer cells RM1, PNEC30, P25.48, MyC-CaP and VCaP cell line of human prostate cancer exhibited different metastatic capacities (10), and were purchased from the American Association for Cancer Research (Philadelphia, PA, USA). Cells were cultured in Dulbecco's modified Eagle's medium containing Ham's F12 (Corning Incorporated, Corning, NY, USA), and placed in a $5 \% \mathrm{CO}_{2}$ incubator at $37^{\circ} \mathrm{C}$ and passaged once cells reached confluency. Following the incubation period, cells were resuspended in $0.25 \%$ trypsin/0.02\% EDTA solution for $3 \mathrm{~min}$ at room temperature.

Total RNA extraction and quantitative polymerase chain reaction $(q P C R)$. RNA was isolated using TRIzol ${ }^{\mathrm{TM}}$ Reagent (15596026, Invitrogen; Thermo Fisher Scientific, Inc., Waltham, MA, USA) according to the manufacturer's protocol. cDNA was prepared from primary cultured astrocytes using Fast Lane Cell cDNA Kit (Qiagen, CA, USA) by using 500 ng RNA, and levels of mRNA were assessed using SYBR supermix (1708880, Bio-Rad, CA, USA). The thermocycling conditions were as follows: $95^{\circ} \mathrm{C}$ for $3 \mathrm{~min}, 39$ cycles of $95^{\circ} \mathrm{C}$ for $30 \mathrm{sec}, 60^{\circ} \mathrm{C}$ for $30 \mathrm{sec}$ and $72^{\circ} \mathrm{C}$ for $30 \mathrm{sec}$. The following forward $(\mathrm{F})$ and reverse $(\mathrm{R})$ primers were used to amplify CTGF and actin: CTGF (F) 5-GATGTACGGAGA CATGGCGT-3, CTGF (R) 5-AGTAGGCACACTGCTGCT TT-3 (primer blast, NCBI, USA); actin (F) 5-GAGATTACT GCCCTGGCTCCTA-3, actin (R) 5-TCATCGTACTCCTGC TTGCTGAT-3 (11) (Invitrogen, Thermo Fisher Scientific, Inc.). Gene level was calculated using the $2^{-\Delta \Delta \mathrm{Cq}}$ method and presented as relative fold change (12).

Western blotting. Total protein was extracted from RM1, PNEC30 and P25.48 cell lines using RIPA buffer (Beyotime, Beijing, China). The protein concentration was determined using a bicinchoninic acid protein assay kit. Protein samples $(10 \mu \mathrm{g})$ were separated using denaturing SDS-PAGE $(10 \%$ gel) and transferred onto a polyvinylidene fluoride membrane. The membrane was blocked in PBS/5\% skimmed milk at room temperature for $1 \mathrm{~h}$, followed by an incubation period with primary antibody (anti-CTGF: 1:1,000; cat. no. ab6992; Abcam, Cambridge, UK) and $\alpha$-tubulin (T9026, 1:5,000, Sigma-Aldrich, Merck KGaA, Darmstadt, Germany) overnight at $4^{\circ} \mathrm{C}$. Secondary antibody (anti-rabbit horseradish peroxidase conjugated antibody, 1:5,000; cat. no. ab99848; Abcam and anti-mouse HRP antibody, 1:5,000; Bio-Rad Laboratories, Inc., Hercules, CA, USA) was added prior to incubation at room temperature for $1 \mathrm{~h}$. Protein was visualized using enhanced chemiluminscence reagent (Thermo Fisher Scientific, Inc., Waltham, MA, USA). Expression levels of protein were analyzed using ImageJ analysis software (V.2.1.4.7, National Institutes of Health, Bethesda, MD, USA).

Immunohistochemical analysis. Paraffin specimens confirmed by pathology were collected from a patient with prostate cancer which had metastasized to the bone. Patient was male, 55 years old, and the sample was collected at the Department of Orthopedic Surgery at The First Hospital of Qiqihaer City (Quiqihaer, China) in December 2015. Paraffin specimens (fixed in $4 \%$ paraformaldehyde at $4^{\circ} \mathrm{C}$ for at least $48 \mathrm{~h}$ and then were cut into $5 \mu \mathrm{m}$ thick slices) were processed using anti-CTGF immunohistochemical staining. Subsequent to being blocked using $2 \%$ bovine serum albumin at room temperature for $1 \mathrm{~h}$ (BSA; Amresco, LLC, Solon, OH, USA), the primary antibody, anti-CTGF antibody (1,400; cat. no. ab6992; Abcam), was applied to the specimens overnight at $4^{\circ} \mathrm{C}$. Following incubation, the secondary antibody, biotin-labeled sheep anti-mouse antibody (1:1,000; cat no. A0277s; Beyotime Institute of Biotechnology, Haimen, China), was added. All photographs were captured using a Zeiss Axioplan 2 microscope (Carl Zeiss AG, Oberkochen, Germany). Immunostained slides were analyzed using the Image-Pro Plus system (Media Cybernetics, Inc., Rockville, MD, USA).

Cell proliferation assay. An automated cell counter (Cellometer; Nexcelom Bioscience LLC, Lawrence, MA, USA) was used to analyze cell proliferation. RM1 cells $\left(8 \times 10^{3}\right.$ cells/well $)$ were transfected with empty vector or stable overexpression of CTGF in 12-well plates and incubated for $48 \mathrm{~h}$. Following incubation, a number of cells $\left(5 \times 10^{6}\right)$ were removed daily for a total of 4 days, for further experiments.

Tumor metastasis assay. A C57BL/6 mouse model carrying a form of bone metastasis, developed according to Kubota and Takigawa (5), was used to investigate prostate cancer and orthotopic implantation. The model was established by the subcapsular implantation of histologically intact prostate tumor tissues into the prostate gland of C57BL6 syngeneic mice (male; Vital River, Beijing, China; 20-25 g; 2-3 months old). The numbers of mice were $13,14,52,56$ respectively (Fig. 4A), the diameter of tumor pieces were $<3 \mathrm{~mm}$, which were harvested from a subcutaneous tumor by RM1 cells. All animals were maintained on a 12 -h light/dark cycle at $20-25^{\circ} \mathrm{C}$ and had free access to food and water. The subcutaneous implantation model was used as a control. Alterations in carcinoma tumor volume(s) (volume calculation formula: $\pi \mathrm{LW} 2 / 6$, where $\mathrm{L}$ is length and $\mathrm{W}$ is width) in situ and the survival rate time(s) were recorded. X-radiography (XPERT80-L; Kubtec, Stratford, CT, USA) was used to record radiographs on the effects of implantation after 7 days. Bone samples from the model were collected and fixed in $4 \%$ paraformaldehyde overnight at room temperature. Samples were stored in $70 \%$ ethanol, embedded in paraffin, sagittally sectioned at $7 \mu \mathrm{m}$, and stained with hematoxylin and eosin, according to standard methods (13). Samples were imaged using a Zeiss Axioplan 2 microscope (Carl Zeiss, Inc., Thornwood, NY, USA).

Osteoblast differentiation. Bone marrow cells $\left(2-4 \times 10^{5}\right)$ were obtained from mouse tibia and femur. Following overnight culture, $50 \mathrm{ng} / \mathrm{ml}$ ascorbic acid (AA; Merck KGaA) which was 
A

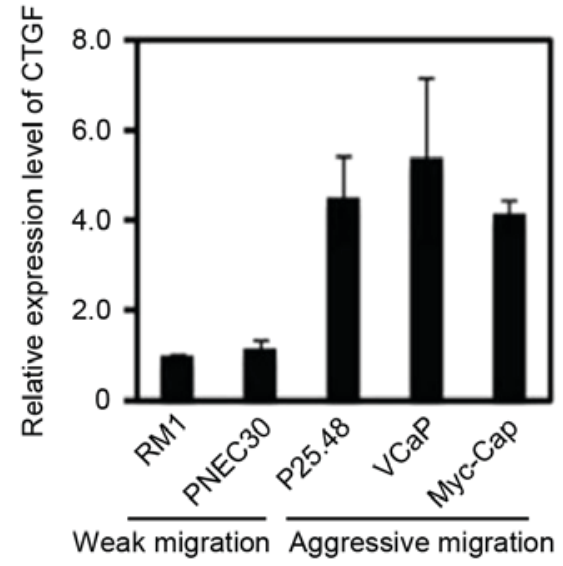

C

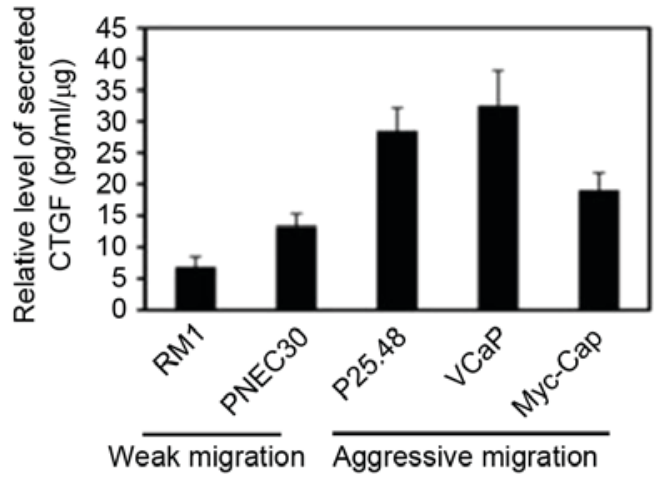

B

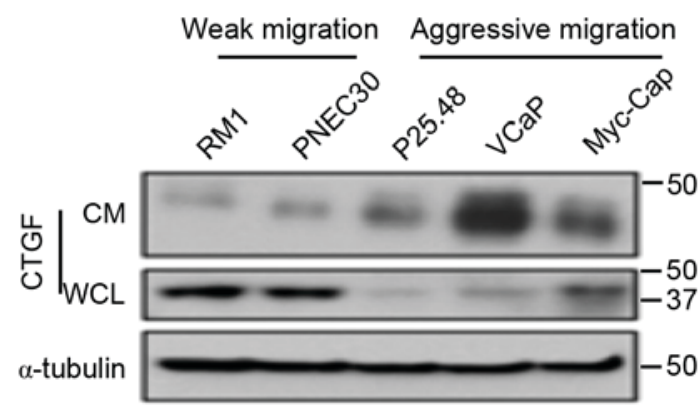

Figure 1. Increased levels of CTGF expression in highly metastatic prostate cancer cells. (A) mRNA levels of CTGF in several bone metastatic prostate cancer cells. (B) CTGF protein levels in culture supernatant and whole cell lysate of several bone metastatic prostate cancer cells. (C) Secreted CTGF levels using ELISA in cell culture supernatant of several bone metastatic prostate cancer cells. CM, culture supernatant; WCL, whole cell lysate; CTGF, connective tissue growth factor.

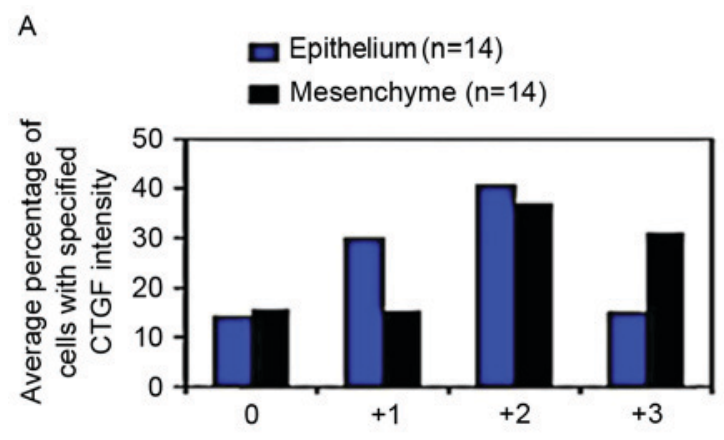

B

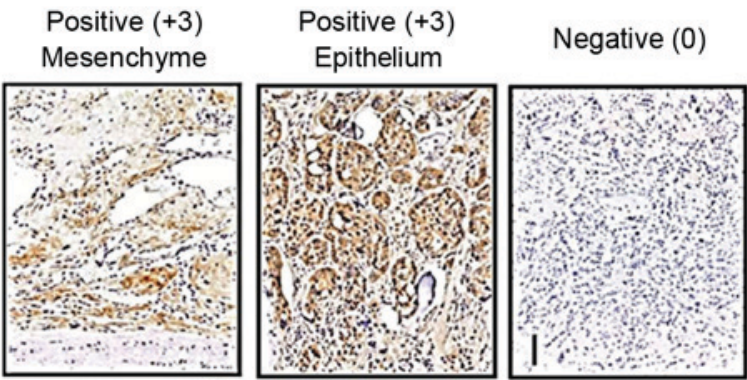

Figure 2. CTGF expression levels in patients with prostate cancer and bone metastasis. (A) Statistical analysis of CTGF intensity in epithelial and mesenchymal cells. (B) Representative images of different degrees of staining in CTGF immunohistochemistry samples. CTGF, connective tissue growth factor. Magnification: $\mathrm{x} 100$; scale $\mathrm{bar}=25 \mu \mathrm{m}$. able to induce the differentiation of osteoblast cells, was added, and $600 \mathrm{ng} / \mathrm{ml} \mathrm{BSA} \mathrm{(Amresco,} \mathrm{LLC)} \mathrm{and} 600 \mathrm{ng} / \mathrm{ml} \mathrm{CTGF}$ were added to the control group and experimental group respectively every 2 days for a 9-day period. Cells were fixed with 4\% paraformaldehyde for $10 \mathrm{~min}$ at room temperature, washed with PBS and then alkaline phosphatase (ALP) staining was performed using Fast Red (F4381; Merck KGaA), according to the manufacturer's protocol. Image analysis software BIOQUANT Imaging Extensions (Bioquant Image Analysis Corporation, Nashville, TN, USA) was used to perform statistical analysis and calculate the mean covering rate.

Statistical analysis. Statistical analysis was performed using SPSS (version 16.0; SPSS, Inc., Chicago, IL, USA). All measurement data are presented as the mean \pm standard deviation. A paired Student's t-test was used for all measurement data analyzed using VassarStats software (http://vassarstats. net/). Enumeration data were analyzed using the $\chi^{2}$ goodness-of-fit test. All experiments were performed at least three times. $\mathrm{P}<0.05$ indicated a statistically significant difference.

\section{Results}

Increased expression of CTGF in highly metastatic prostate cancer cells. Reverse transcription-qPCR analysis 
A

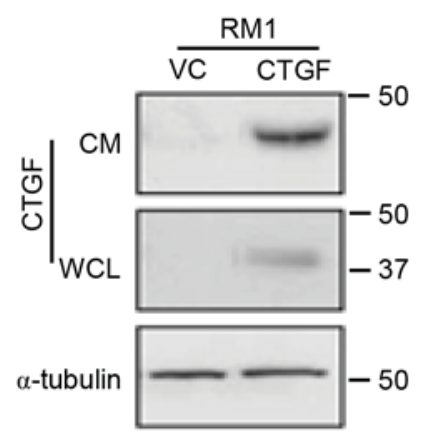

B

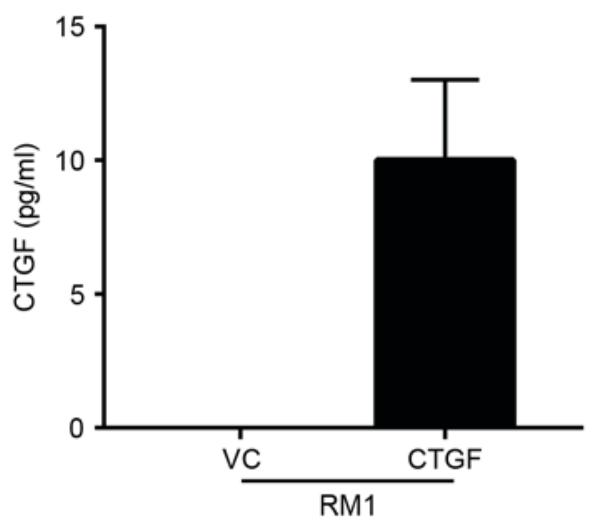

C

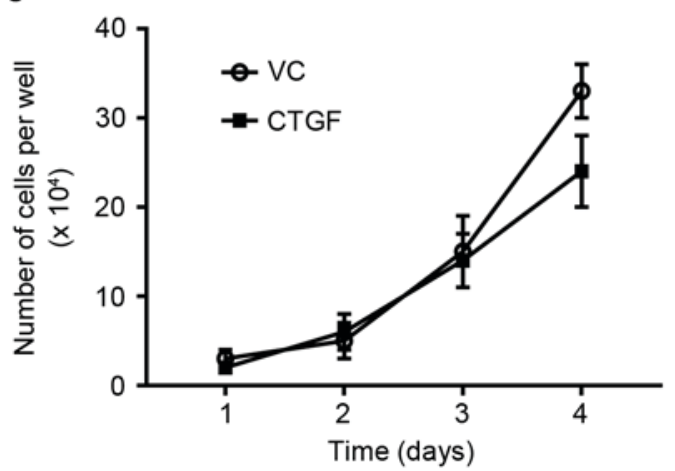

D

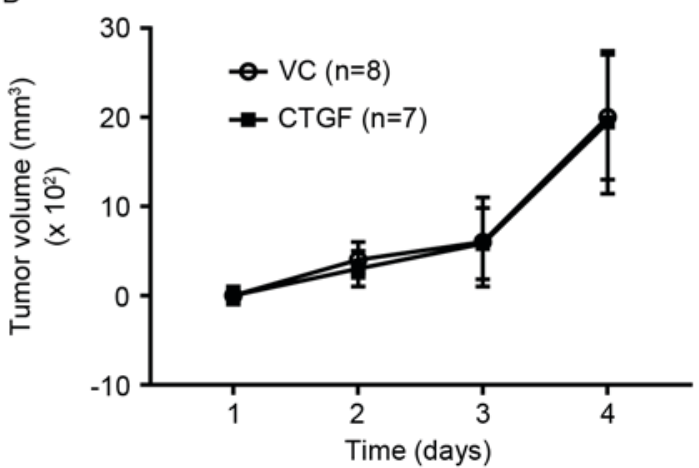

Figure 3. Increased expression level of CTGF does not promote tumor cell proliferation and xenotransplantation. (A) CTGF expression levels in cell culture supernatant and whole RM1 cell lysate. (B) Secreted CTGF levels determined using ELISA in culture supernatant. (C) Cell proliferation experiment. (D) Tumor volume growth following xenotransplantation of RM1 cells. CM, culture supernatant; WCL, whole cell lysate; CTGF, connective tissue growth factor; VC, vehicle control.

demonstrated that CTGF mRNA expression was significantly increased in aggressive bone metastatic prostate cancer cells $(\mathrm{P}=0.032$; Fig. 1A). Western blotting results demonstrated that CTGF protein expression in whole cell lysate and culture supernatant was significantly decreased in high bone metastatic prostate cancer cells $(\mathrm{P}=0.025)$; however, secretory CTGF protein levels in cell culture supernatant was markedly increased compared with prostate cancer cells with a weaker metastatic potential ( $\mathrm{P}=0.0011$; Fig. 1B). In the ELISA, CTGF secreted by aggressively metastatic prostate cancer cells (MyC-CaP, P25.48 and VCaP cell lines) was increased 1.9-fold compared with weakly metastatic prostate cancer cells (RM1 and PNEC30 cell lines; $\mathrm{P}=0.002$; Fig. 1C).

Increased CTGF expression levels in patients with prostate cancer bone metastasis. Immunohistochemical staining detecting CTGF expression levels in clinical samples demonstrated mid to deep staining (scoring 2-4) in bone metastasis samples. Expression of CTGF in mesenchymal cells was markedly increased compared with epithelial cells $(\mathrm{P}=0.013$; Fig. 2A). Results indicate that high CTGF expression levels in mesenchymal and epithelial cells was a common characteristic of prostate cancer with bone metastasis.

Increased CTGF expression levels do not promote tumor cell proliferation and xenotransplantation. RM1 cells were transfected with an empty plasmid and a CTGF plasmid to produce a stable RM1 cell line. CTGF expression in whole cell lysate and culture supernatant was significantly increased in RM1 cells (Fig. 3A and B). The in vitro amplification curve demonstrated that high expression levels of CTGF had no significant effect on the proliferation of tumor cells $(\mathrm{P}>0.05)$. RM1 cell lines that were implanted into mice demonstrated that increased CTGF expression levels would not cause an alteration in tumor volume $(\mathrm{P}>0.05$; Fig. 3C and D).

Increased expression of CTGF promotes bone metastasis in prostate cancer. The incidence of bone metastasis in mice injected with control plasmid was $14 \%(2 / 14)$, whereas mice injected CTGF plasmids had an incidence of $31 \%$ (4/13; Fig. 4A). Bone lesions caused by RM1 cells transfected with control plasmids and CTGF plasmids were significantly different $(\mathrm{P}=0.025)$. The area of tumors with $\mathrm{RM} 1$ cells transfected with CTGF was 1.7-fold larger compared with that with RM1 cells transfected with a control plasmid ( $\mathrm{P}=0.018$; Fig. 4B). Results demonstrate that CTGF may significantly improve the ability of bone metastasis in primary prostate cancer.

CTGF causes dysregulation in osteoblast differentiation. ALP staining was used to calculate the mean coverage of osteoblast differentiation. The ability of osteoblast differentiation significantly increased following the addition of AA $(\mathrm{P}=0.006$; Fig. 5A and B). However, when adding AA and CTGF simultaneously, the staining area was significantly decreased as the 
A
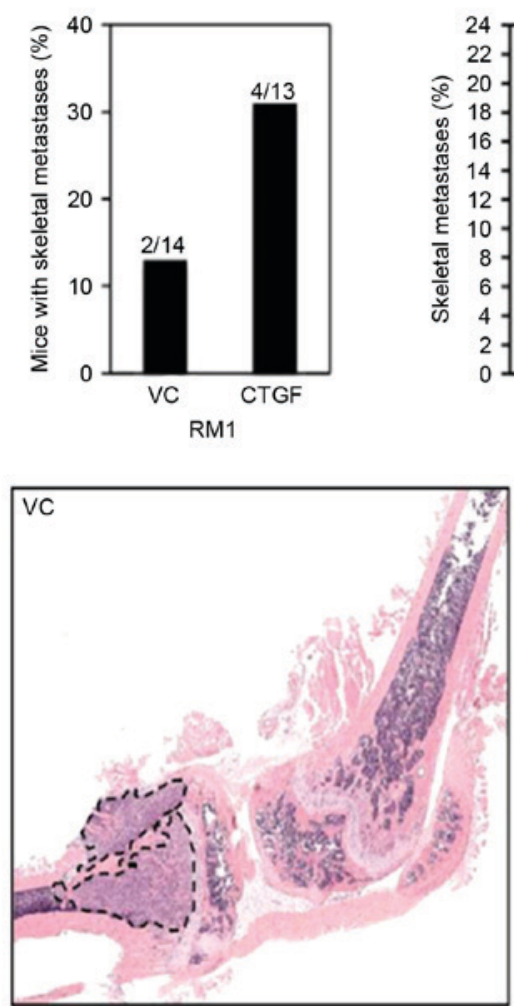
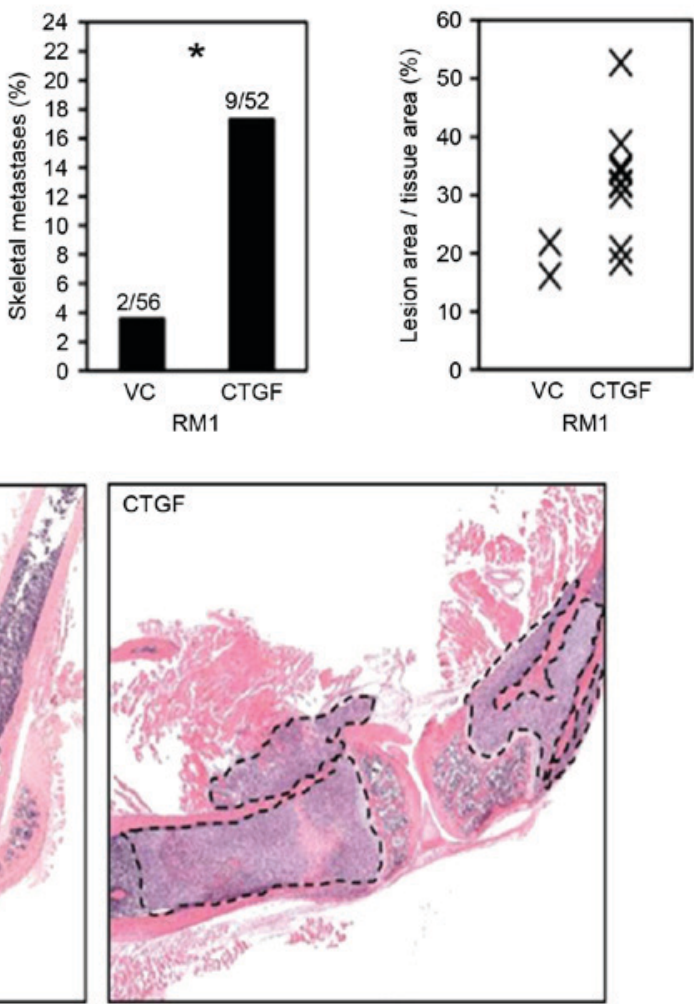

Figure 4. Increased expression levels of CTGF promotes bone metastasis in primary prostate cancer. (A) The effect of CTGF overexpression in bone metastasis and pathological lesions. (B) The effect of CTGF overexpression on tumor areas. " $\mathrm{P}<0.05$. VC, vehicle control; CTGF, connective tissue growth factor.

A

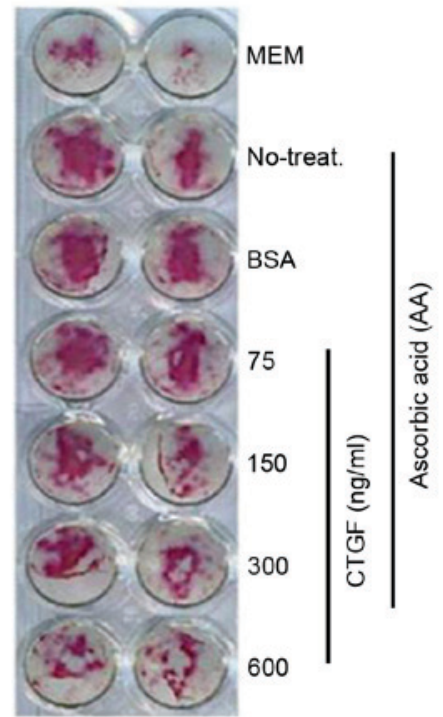

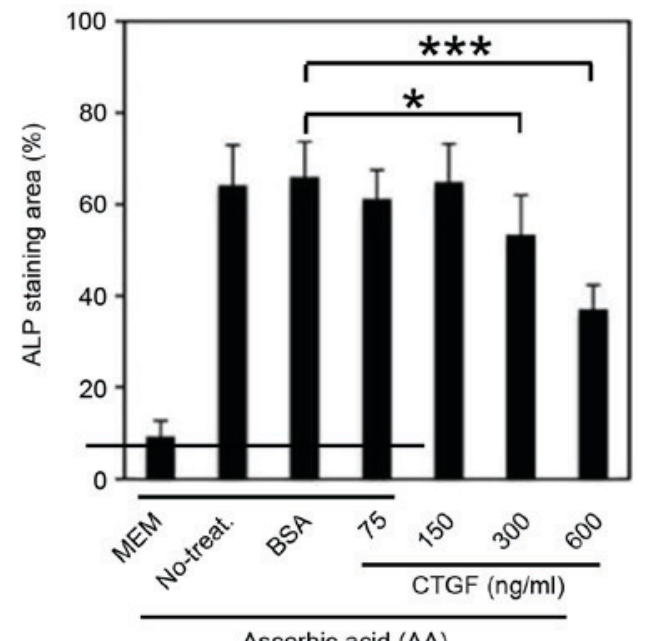

Figure 5. CTGF leads to a dysregulation in osteoblast differentiation. (A) Osteoblast differentiation experiment using ALP staining. (B) Quantification of ALP staining. ${ }^{*} \mathrm{P}<0.05,{ }^{* * * *} \mathrm{P}<0.001$. BSA, bovine serum albumin; CTGF, connective tissue growth factor; AA, ascorbic acid; ALP, alkaline phosphatase; MEM, medium.

concentration of CTGF increased $(\mathrm{P}=0.014)$. Results demonstrated that CTGF promoted prostate cancer bone metastasis by causing dysregulation in osteoblast differentiation.

\section{Discussion}

The association between CTGF expression levels and prostate cancer with bone metastasis has been investigated previously (14). Previous reports demonstrated that CTGF increased in cancer tissue (15), which is consistent with the results of the present study, and it had different regulation abilities and effects on different types of tumor cell (16-19). Bennewith et al (20) demonstrated that CTGF protects cells from hypoxia-mediated apoptosis, providing an in vivo selection for tumor cells that express high levels of CTGF. Meanwhile, Kwon et al (21) revealed that CTGF is induced 
by TGF- $\beta$ in diverse cell types, and CTGF was impaired in pancreatic cancers and cell lines. In different types of cancer cell, particularly breast and prostate, there are increased levels of CTGF expression, which are associated with a poor clinical outcome for patients $(22,23)$. Furthermore, previous research demonstrated that CTGF had an association with vasculogenesis, infiltration and metastasis of malignancy tumor (24).

Results from the present study demonstrated that the transcription and expression levels of CTGF were increased in prostate cancer cells that were highly metastatic, and the level of CTGF secreted from these cells was increased 1.7-fold compared with prostate cancer cells that had a decreased metastatic ability (low metastasis). This indicated that CTGF may be able to promote metastasis and invasion of prostate cancer. Increased CTGF expression levels in liver cancer, brain glioma and infiltrative gastric carcinoma may exacerbate medical conditions and decrease overall survival rates compared with diseases that have low levels of CTGF (25). Results of the present study suggested that the same biological functions of CTGF are present in prostate cancer cells and that high levels of expression are present in highly metastatic cells. Increased expression levels of CTGF was the primary characteristic of prostate cancer bone metastasis, with no significant difference between mesenchymal and epithelial cells.

CTGF may promote the occurrence, differentiation, proliferation, pathological fracture healing and bone mass maintenance of cartilage and osteogenesis. Overexpression of CTGF may promote the expression of type X collagen in HCS-2/8 chondrosarcoma cells and the secretion of chondroproteoglycan (26). CTGF also promotes the adhesion of osteoblasts by inhibiting the combination of fibrinogen and integrin receptors and inhibit the synthesis of osteocalcin in rat osteoblast-like cells (27). Collectively, these previous studies indicate that CTGF serves a key function in regulating bone transformation and metastasis.

The present study demonstrated that increased expression levels of CTGF were not able to promote the proliferation of cancer cells, and also had no influence on alterations in tumor volume by xenotransplantation of RM1 cells. However, increased levels of CTGF expression may be able to promote bone metastasis in primary prostate cancer. Furthermore, ALP staining experiments demonstrated that bone metastasis in prostate cancer was caused by the dysregulation of osteoblast differentiation. However, further research is required to clarify the underlying molecular mechanism(s) of CTGF in promoting bone formation.

In summary, the results of the present study identified that CTGF promotes the bone metastatic process of prostate cancer by dysregulating the differentiation of osteoblasts, and forms tumor microenvironment characteristics for osteolytic metastatic carcinoma. These identified characteristics provide an evidence base for the development of effective prevention strategies and therapeutic options for patients with prostate cancer, as well as having important implications in the prevention of bone metastasis.

\section{Acknowledgements}

The present study was supported by a Harbin First Hospital talent introduction funded project (grant no. 2013SYYRCYJ01-1).

\section{References}

1. Vickers AJ, Sjoberg DD, Ulmert D, Vertosick E, Roobol MJ, Thompson I, Heijnsdijk EA, De Koning H, Atoria-Swartz C, Scardino PT and Lilja H: Empirical estimates of prostate cancer overdiagnosis by age and prostate-specific antigen. BMC Med 12: 26, 2014.

2. Cives M, Rizzo F, Simone V, Bisceglia F, Stucci S, Seeber A, Spizzo G, Montrone T, Resta L and Silvestris F: Reviewing the osteotropism in neuroendocrine tumors: The role of epithelial-mesenchymal transition. Neuroendocrinology 103: 321-334, 2016.

3. Chen CC and Lau LF: Functions and mechanisms of action of CCN matricellular proteins. Int J Biochem Cell Biol 41: 771-783, 2009.

4. Holbourn KP, Acharya KR and Perbal B: The CCN family of proteins: Structure-function relationships. Trends Biochem Sci 33: 461-473, 2008

5. Kubota $\mathrm{S}$ and Takigawa M: The role of $\mathrm{CCN} 2$ in cartilage and bone development. J Cell Commun Signal 5: 209-217, 2011.

6. Hou R, Wang YW, Liang HF, Zhang ZG, Liu ZM, Zhang BH, Zhang BX and Chen XP: Animal and cellular models of hepatocellular carcinoma bone metastasis: Establishment and characterisation. J Cancer Res Clin Oncol 141: 1931-1943, 2015.

7. Jun JI and Lau LF: Taking aim at the extracellular matrix: $\mathrm{CCN}$ proteins as emerging therapeutic targets. Nat Rev Drug Discov 10: 945-963, 2011

8. Tai HC, Chang AC, Yu HJ, Huang CY, Tsai YC, Lai YW, Sun HL, Tang $\mathrm{CH}$ and Wang SW: Osteoblast-derived WNT-induced secreted protein 1 increases VCAM-1 expression and enhances prostate cancer metastasis by down-regulating miR-126. Oncotarget 5: 7589-7598, 2014.

9. Ren L, Wang X, Dong Z, Liu J and Zhang S: Bone metastasis from breast cancer involves elevated IL-11 expression and the gp130/STAT3 pathway. Med Oncol 30: 634, 2013.

10. Gao YB, Xiang ZL, Zhou LY, Wu ZF, Fan J, Zeng HY and Zeng ZC: Enhanced production of CTGF and IL-11 from highly metastatic hepatoma cells under hypoxic conditions: An implication of hepatocellular carcinoma metastasis to bone. J Cancer Res Clin Oncol 139: 669-679, 2013.

11. Wang X, Sha L, Sun N, Shen Y and Xu Q: Deletion of mTOR in reactive astrocytes suppresses chronic seizures in a mouse model of temporal lobe epilepsy. Mol Neurobiol 54: 175-187, 2017.

12. Schmittgen TD and Livak KJ: Analyzing real-time PCR data by the comparative C(T) method. Nat Protoc 3: 1101-1108, 2008.

13. Fischer AH, Jacobson KA, Rose J and Zeller R: Hematoxylin and eosin staining of tissue and cell sections. CSH Protoc 2008: pdb.prot4986, 2008

14. Juárez P, Mohammad KS, Yin JJ, Fournier PG, McKenna RC, Davis HW, Peng XH, Niewolna M, Javelaud D, Chirgwin JM, et al: Halofuginone inhibits the establishment and progression of melanoma bone metastases. Cancer Res 72: 6247-6256, 2012.

15. Chien W, O'Kelly J, Lu D, Leiter A, Sohn J, Yin D, Karlan B, Vadgama J, Lyons KM and Koeffler HP: Expression of connective tissue growth factor $(\mathrm{CTGF} / \mathrm{CCN} 2)$ in breast cancer cells is associated with increased migration and angiogenesis. Int $\mathrm{J}$ Oncol 38: 1741-1747, 2011.

16. Cawthorn TR, Amir E, Broom R, Freedman O, Gianfelice D, Barth D, Wang D, Holen I, Done SJ and Clemons M: Mechanisms and pathways of bone metastasis: Challenges and pitfalls of performing molecular research on patient samples. Clin Exp Metastasis 26: 935-943, 2009.

17. Fong YC, Lin CY, Su YC, Chen WC, Tsai FJ, Tsai CH, Huang CY and Tang $\mathrm{CH}$ : CCN6 enhances ICAM-1 expression and cell motility in human chondrosarcoma cells. J Cell Physiol 227: 223-232, 2012

18. Mohammad KS, Javelaud D, Fournier PG, Niewolna M, McKenna CR, Peng XH, Duong V, Dunn LK, Mauviel A and Guise TA: TGF-beta-RI kinase inhibitor SD-208 reduces the development and progression of melanoma bone metastases. Cancer Res 71: 175-184, 2011.

19. Gorlov IP, Sircar K, Zhao H, Maity SN, Navone NM, Gorlova OY, Troncoso P, Pettaway CA, Byun JY and Logothetis CJ: Prioritizing genes associated with prostate cancer development. BMC Cancer 10: 599, 2010.

20. Bennewith KL, Huang X, Ham CM, Graves EE, Erler JT, Kambham N, Feazell J, Yang GP, Koong A and Giaccia AJ: The role of tumor cell-derived connective tissue growth factor (CTGF/CCN2) in pancreatic tumor growth. Cancer Res 69: 775-784, 2009.

21. Kwon S, Munroe X, Crawley SC, Lee HY, Spong S, Bradham D, Gum JR Jr, Sleisenger MH and Kim YS: Expression of connective tissue growth factor in pancreatic cancer cell lines. Int $\mathrm{J}$ Oncol 31: 693-703, 2007. 
22. Tan TW, Lai CH, Huang CY, Yang WH, Chen HT, Hsu HC, Fong YC and Tang CH: CTGF enhances migration and MMP-13 up-regulation via alphavbeta3 integrin, FAK, ERK, and NF-kappaB-dependent pathway in human chondrosarcoma cells. J Cell Biochem 107: 345-356, 2009.

23. Shimo T, Kubota S, Yoshioka N, Ibaragi S, Isowa S, Eguchi T, Sasaki A and Takigawa M: Pathogenic role of connective tissue growth factor (CTGF/CCN2) in osteolytic metastasis of breast cancer. J Bone Miner Res 21: 1045-1059, 2006.

24. Bartholin L, Wessner LL, Chirgwin JM and Guise TA: The human Cyr61 gene is a transcriptional target of transforming growth factor beta in cancer cells. Cancer Lett 246: 230-236, 2007.

25. Kang Y, Siegel PM, Shu W, Drobnjak M, Kakonen SM, Cordón-Cardo C, Guise TA and Massagué J: A multigenic program mediating breast cancer metastasis to bone. Cancer Cell 3: 537-549, 2003.
26. Manara MC, Perbal B, Benini S, Strammiello R, Cerisano V, Perdichizzi S, Serra M, Astolfi A, Bertoni F, Alami J, et al: The expression of cen3(nov) gene in musculoskeletal tumors. Am J Pathol 160: 849-859, 2002.

27. Inoue $\mathrm{M}$, Otsuka $\mathrm{K}$ and Shibata $\mathrm{H}$ : Circulating tumor cell count as a biomarker of a specific gastric cancer subgroup characterized by bone metastasis and/or disseminated intravascular coagulation-an early indicator of chemotherapeutic response. Oncol Lett 11: 1294-1298, 2016.

(i) (9) This work is licensed under a Creative Commons Attribution-NonCommercial-NoDerivatives 4.0 International (CC BY-NC-ND 4.0) License. 